\title{
Insights into chitosan hydrogels on dentine bond strength and cytotoxicity
}

\author{
V. Tamara Perchyonok ${ }^{1}$, Sias Grobler ${ }^{2}$, Shengmiao Zhang ${ }^{3}$, Annette Olivier ${ }^{2}$, Theunis Oberholzer ${ }^{4}$ \\ ${ }^{1}$ VTPChem PTY Ltd., Melbourne, Australia \\ ${ }^{2}$ Oral and Dental Research Institute, Faculty of Dentistry, University of the Western Cape, Cape Town, South Africa \\ ${ }^{3}$ School of Material Science and Engineering, East China University of Science and Technology, Shanghai, China \\ ${ }^{4}$ School of Dentistry and Oral Health, Griffith University, Gold Coast, Australia \\ Email: tamaraperchyonok@gmail.com
}

Received 25 January 2013; revised 28 February 2013; accepted 11 March 2013

\begin{abstract}
Contemporary dental adhesives show favorable immediate results in terms of bonding effectiveness. However, the durability of resin-dentin bonds is their major problem. Materials and Methods: Preparation of 3 chitosan-antioxidant hydrogels was achieved using modified hydrogel preparation method. Their effect on the bond strength to dentine both short term (after 24 hours) and long term (after 6 months) were evaluated using shear bond strength measurements using Instron Universal Testing Mascine). The SEM was used to study the surface of the hydrogels. The cell survival rate (cytotoxicity) of the antioxidants resveratrol, $\beta$-carotene and propolis towards Balb/c 3T3 mouse fibroblast cells was also assessed using the standard MTT assay. Results: It was found that chitosan-H treated dentine gives significantly $(p<0.05$; Non-parametric ANOVA test) higher shear bond values than dentine treated or not treated with phosphoric acid. The anti-oxidants chitosan hydrogels improved the shear bond strength. Overall, there was a relapse in the shear bond strength after 6 months. The SEM study showed that the hydrogel formulations have a uniform distribution of drug content, homogenous texture and yellow color. The $\mathrm{pH}$ of the growth medium adjusted to relevant values had a highly significant influence (Tukey-Kramer MultipleComparison Test; $p<0.01$ ) on the cell survival rate of Balb/c mouse 3T3 fibroblast cells and therefore most probably also to tooth pulp fibroblast cells. The lower the $\mathbf{p H}$ value the higher the negative influence. Furthermore, the sequence of survival rate was found to be: $\beta$-carotene $(92 \%)>$ propolis $(68 \%)>$ resveratrol (33\%). Conclusion: the antioxidant-chitosan hydrogels significantly improved bonding to dentine with or without phosphoric acid treatment. The $\mathrm{pH}$ of the growth medium had a high influence on the cell sur-
\end{abstract}

vival rate of Balb/c mouse 3T3 fibroblast cells. The release of the antioxidant $\beta$-carotene would not have an influence on the pulp cells. These materials might address the current perspectives for improving bond durability.

Keywords: Antioxidant-Chitosan Hydrogels; SEM; Bond Strength; Cytotoxicity; Mouse 3T3 Fibroblast Fibroblast

\section{INTRODUCTION}

The majority of protocols for dentine bonding requires acid etching that removes the smear layer and smear plugs and decalcifies the underlying dentinal structures. Peritubular dentine is partially removed and the dentinal tubules acquire a funnel-shaped appearance. Concomitantly, intertubular dentine is etched up to a depth of 5 $\mathrm{mm}$ that exposes a collagen-based organic matrix. The consequent application of the resin monomers results in the so-called hybrid layer $[1,2]$ or inter-diffusion zone [3]. However, it has been proposed that resins may not penetrate into the exposed matrix as deeply as do acidic conditioners [4-6]. This incomplete penetration of the monomers would result in zones susceptible to hydrolytic degradation and ultimately would produce areas of nanoleakage [5]. Removal of the exposed organic matrix or reduction of its thickness may possibly minimize this problem. Some authors have shown that the thickness of the exposed organic matrix or the thickness of hybrid layer is not important to obtain good strengths values [7]. In addition, recent studies have shown that acid etching does not remove all the organic components of smear layer; the disorganized collagen is only denatured by the acids and remains on the dentinal surface [5].

Bioadhesive polymers appear to be particularly attractive for the development of alternative etches free dentin bonding system with an added advantage of additional 
therapeutic delivery systems to improve intradental administration of therapeutic and prophylactic agents if necessary [8]. Chitosan, which is a biologically safe biopolymer, has been proposed as a bioadhesive polymer and are of continuous interest to us due to there unique properties and flexibility in broad range of oral applications reported by others and us recently [9].

Null Hypothesis: Compromised sealing ability of composite restorations could be reversed through application of chitosan-antioxidant hydrogels on the bond strength of a composite resin to dentine in the etch-free protocol. In parallel, to assess the ability of the 3 chitosan-antioxidant hydrogels to improve the bond strength following the conventional etch/primer/bonding sequence. In order to asses the biocompatible nature of the newly developed functional materials, to investigate the nature of the hydrogels through SEM and fourthly to assess the cytotoxicity of the 3 antioxidants (resveratrol, $\beta$-carotene and propolis) towards Balb/c 3T3 mouse fibroblast cells.

\section{MATERIALS and METHODS}

\subsection{Preparation of Chitosan Based Gels with Resveratrol, $\beta$-Carotene or Propolis as Potential Substrate for Bonding to Dentin}

Antioxidant (resveratrol, $\beta$-carotene or propolis) gels were prepared by dispersion of corresponding antioxidant powder 0.2 grams in glycerol $(5 \% \mathrm{w} / \mathrm{w})$ using a mortar and a pestle. Ten milliliters of glacial acetic acid $(3 \% \mathrm{w} / \mathrm{w})$ was then added with continuous mixing and finally chitosan polymer was spread on the surface of the dispersion and mixed well to form the required gel. Corresponding antioxidant gel had been prepared with 5 $\% \mathrm{w} / \mathrm{w}$ concentrations of chitosan gelling agent. The various amounts of BSA and corresponding antioxidant were incorporated into the mixture and the summary of the newly prepared materials is highlighted in Table $\mathbf{1}$. Glacial acetic acid was added to the preparation to obtain the homogenous clear chitosan gel.

Gels $\left(0.5 \mathrm{~g} / \mathrm{L} \mathrm{cm}^{2}\right)$ were poured into petri-dishes and were dried at room temperature (Table 1).

\subsection{Determination of Gel $\mathbf{p H}$}

One gram of the prepared gels was also weighed and dispersed in $10 \mathrm{ml}$ of purified water. The $\mathrm{pH}$ of the dispersions was measured using a combination $\mathrm{pH}$ glass electrode coupled to a potentiometer (HANNA instruments, HI8417, Portugal).

\subsection{Morphology of the Gels}

The samples were prepared by freezing in liquid nitrogen for $10 \mathrm{~min}$, and then were freeze-dried for $24 \mathrm{~h}$. The
Table 1. Gel formulation prepared in the study.

\begin{tabular}{ccccc}
\hline Gel formulation & & $\begin{array}{c}\text { Chitosan } \\
\text { concentration }\end{array}$ & Medium & $\mathrm{pH}$ \\
\hline Chitosan-H & Gel-1 & 5 & $1 \%$ acetic acid & 4.00 \\
$\begin{array}{c}\text { Chitosan-H + } \\
\text { Resveratrol }\end{array}$ & Gel-2 & 5 & $1 \%$ acetic acid & 4.16 \\
$\begin{array}{c}\text { Chitosan-H }+ \\
\text { Propolis } \\
\begin{array}{c}\text { Chitosan-H + } \\
\beta \text {-carotene }\end{array}\end{array}$ & Gel-3 & 5 & $1 \%$ acetic acid & 4.63 \\
\hline
\end{tabular}

prepared samples were fractured in liquid nitrogen using a razor blade. The fractured samples were attached to metal stubs, and sputter coated with gold under vacuum for SEM. The interior and the surface morphology were observed in scanning electron microscope (SEM, Hitachi S4800, Japan).

\subsection{Shear Bond Strength Tests for Dentine Bonding}

Extracted non-carious, intact, human molars stored in water containing a few crystals of thymol at $4^{\circ} \mathrm{C}$ were used within two months. Samples were checked before use for any damage caused by their removal. The roots of the teeth were removed with a separating disc and the occlusal enamel removed by grounding wet on 60 -grit silicon carbide $(\mathrm{SiC})$ paper. The teeth were embedded in PVC (Consjit Tubing, SA PVC, JHB, RSA) pipe containers with cold cure acrylic resin so that the ground occlusal surfaces projected well above the resin. The 10 $\mathrm{mm}$ length pipes were put on a glass surface with one end blocked by the glass and the embedding done through the open end. Immediately after embedding the occlusal surfaces were ground wet with 180-grit followed by 600 -grit $\mathrm{SiC}$ on a polishing machine to expose the superficial dentin. The samples were washed under a stream of tap water. A standardized zig (Ultradent ISO A2-70) with an internal diameter of $2.5 \mathrm{~mm}$ and height of $3 \mathrm{~mm}$ was used to shape the composite resin stud (SDR, Dentsply, CA, USA, Batch number 1105000609, Exp 2013-04). Two of these studs were then bonded to the polished dentine surface of each tooth via the bonding agent XP bond (Dentsply, New York, USA), as suggested by the manufacturer. The bonding agent contains: carboxylic acid modified dimethacrylate (TCB resin), phosphoric acid modified acrylate resin (PENTA), urethane dimetacrylate (UDMA), triethyleneglycol dimethacrylate (TEGDMA), 2-hydroxyethylmethacrylate (HEMA), butylated benzenediol (stabilizer), ethyl-4-dimethylaminobenzoate), camphorquinone, functionalized amorphous silica, t-butanol.

In this way were 80 teeth samples (each containing 2 studs) prepared and divided into 10 groups of 8 each, A, 
B, C, D, E, F, J, K, L and M. (Table 2) and stored in a solution of artificial saliva. These groups were then treated as outlined in Table 1. After 24 hours one stud of each tooth was tested for shear bond strength and the other one after 6 months. An Instron Universal Testing Machine (address) at a crosshead speed of $0.5 \mathrm{~mm} /$ minute was used to test the de-bonding strength. All data tests were analysed using the non-parametric ANOVA test.

Cytotoxicity studies of resveratrol, $\beta$-carotene and propolis towards Balb/c 3T3 mouse fibroblast cells.

pH Determination of antioxidant (resveratrol, $\beta$ carotene and propolis) solutions.

One mg of each of resveratrol, $\beta$-carotene and propolis were dissolved in $1 \mathrm{ml}$ of water and the $\mathrm{pH}$ determined with a combination $\mathrm{pH}$ glass-electrode. Three replicates were done on each and the average value noted.

\subsection{Cell Maintenance and Culture}

A Balb/c 3 T3 mouse fibroblast cell line (The National Repository for Biological Materials, Sandringam) was maintained and cultured in standard conditions $\left(37^{\circ} \mathrm{C}\right.$ under 5\% carbon dioxide and 95\% humidity) in Dulbecco's Modified Eagles Medium (DMEM). The medium was supplemented with $10 \%$ fetal bovine serum, $1 \%$ penicillin, $1 \%$ streptomycin and $0.2 \%$ fungizone, changed every second day and cells sub-cultured using routine trypsin/EDTA procedures. The $\mathrm{pH}$ of this medium was adjusted when necessary to 8.0.

\subsection{Influence of Different $\mathrm{pH}$ Values on Balb/c 3T3 Mouse Fibroblast Cell Survival Rate}

To test the possible influence of $\mathrm{pH}$ alone on the survival rate of $3 \mathrm{~T} 3$ cells, the cells were grown to near confluency. Then $3 \mathrm{~T} 3$ cells were diluted to a final cell suspension containing approximately $3 \times 10^{5}$ cells $/ \mathrm{ml}$ and plated out in a 96 well plate. The cells were divided into 3 groups and the three filtered mediums which were adjusted to $\mathrm{pH}$ values of 3.3 (group 1), 6.2 (group 2) and 8.0 (group 3 ) were added after 24 hours. These $\mathrm{pH}$ values were those of propolis (3.3), resveratrol (6.2) and $\beta$-carotene
(8.0) dissolved in water. Two hundred $\mu$ of each group ( 3 groups) was added to each of 20 wells in the 96 well plate. After 24 hours the widely used MTT colorimetric assay was used to evaluate cell growth. This assay involves the ability of viable cells to use mitochondrial dehydrogenase enzymes to convert MTT (a soluble tetrazolium salt) to a blue/violet formazan end-product (Mosman [10]). Twenty $\mu 1$ MTT $(5 \mathrm{mg} / \mathrm{ml}$ in phosphatebuffered solution) was added to each well and left for a further 3 hours to incubate at $37^{\circ} \mathrm{C}$. The medium was discarded to eliminate the MTT and the precipitated formazan crystals were solubilized with $100 \mu \mathrm{l} /$ well of dimethylsulfoxide (DMSO). Absorbance was measured at wavelength $540 \mathrm{~nm}$ on a spectrophotometer to determine the number of viable cells. Three replicates were done in each group.

\subsection{Cytotoxicity Test on Resveratrol, $\beta$-Carotene and Propolis}

For the cytotoxicity testing of the 3 antioxidants, the same method as described above was basically used, but the 3 antioxidants were added to the growth medium $(\mathrm{pH}$ $=8.0$ ) at a concentration of $1 \mathrm{mg} / \mathrm{ml}$. Medium, without any antioxidants was used as controls. Again three replicates were done for each antioxidant.

\section{RESULTS}

\subsection{Gels}

Additive (active antioxidant) content in $0.3 \mathrm{~g}$ of the different gel formulations from the prepared formulae was presented in Table 1. The prepared gel formulations have uniform distribution of drug content, homogenous texture and yellow color. The $\mathrm{pH}$ of the formulations of Gel-1 to Gel-4 ranged from to 4 to 5.12 .

\subsection{The Characterization of Additives-Chitosan Hydrogels Used in This Study}

The SEM images were obtained to characterize the microstructure of the freeze-dried additive composite gels

Table 2. Groups tested ( 8 teeth per group).

\begin{tabular}{ll}
\hline Group A & 37\% of phosphoric acid + primer+ bonding immediately (negative control) \\
Group B & Self-etching primer + bonding immediately (positive control) \\
Group C & Gel1 + primer + bonding immediately (chitosan-H) \\
Group D & Gel2 + primer + bonding immediately (chitosan-H + resveratrol) \\
Group E & Gel3 + primer + bonding immediately (chitosan-H + propolis) \\
Group F & Gel4 + primer + bonding immediately (chitosan-H + $\beta$-carotene) \\
Group J & Gel1 + 37\% of phosphoric acid + primer+ Bonding immediately \\
Group K & Gel2 + 37\% of phosphoric acid + primer+ Bonding immediately \\
Group L & Gel3 $+37 \%$ of phosphoric acid + primer+ Bonding immediately \\
Group M & Gel4 $+37 \%$ of phosphoric acid + primer + Bonding immediately \\
\hline
\end{tabular}


(Gel 1 - 4) and are presented in Figure 1. It could be seen that the gels displayed a homogeneously pore structure. It was thought that the micro-porous structure of the gels could lead to high internal surface areas with low diffusional resistance in the gels. The surfaces of the gels were also presented (Figure 1). The "skin" of the gels can be seen, and the collapse of the surface pores may be due to freeze-drying process (artifacts).

\subsection{Shear Bond Strength}

Mean shear bond strength values after 24 hours were listed in Figure 2. A significant increase in bond strength of the dentine treated with all 4 different gels (Figure 2) was found relative to the two groups with the conventionally bonded dentine (i.e. dentine treated with phosphoric acid or not; Groups A and B). Interestingly the increase in bond strength was also observed in the groups treated with phosphoric acid ( $\mathrm{J}$ to $\mathrm{M}$ ), suggesting that there additional benefits associated with chitosan: antioxidant system are in need of further investigations.

A statistically significant difference was found between $\mathrm{C}$ and $\mathrm{D}, \mathrm{E}$, and $\mathrm{F}(\mathrm{p}<0.01)$. Group $\mathrm{C}$ also differed significantly from $J(p<0.01)$. A significant difference was also found between groups $\mathrm{J}$ and $\mathrm{K}, \mathrm{L}$ and $\mathrm{M}$ $(\mathrm{p}<0.01)$. To summarize the above, phosphoric acid treatment did not give additional benefit to the shear bond strength of dentine (compare groups $\mathrm{A}$ and $\mathrm{B}$ ). It was found that chitosan- $\mathrm{H}$ treated dentine gives higher values than dentine treated with phosphoric (A) acid or not (B). While chitosan-H treated dentine plus phosphoric acid treatment $(\mathrm{J})$ gave higher values than dentine not

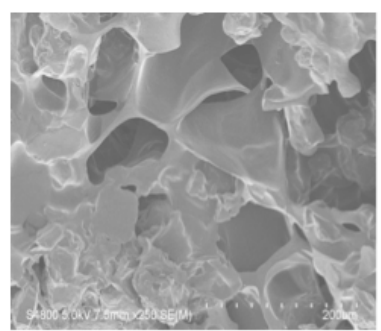

(a)

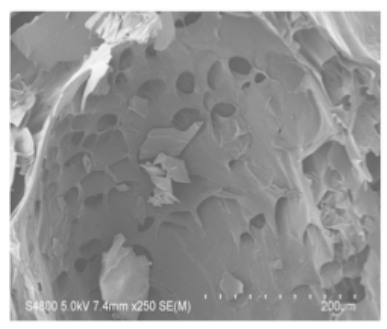

(c)

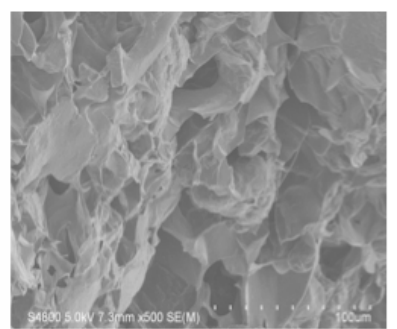

(b)

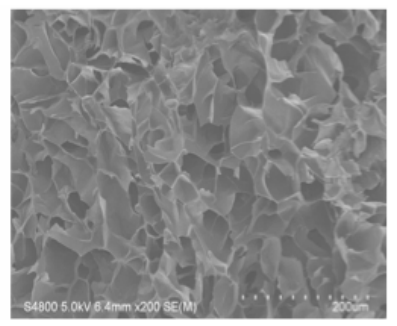

(d)
Figure 1. SEM photographs of interior morphology of the selected gels under investigation for (a) Gel-1; (b) Gel-2; (c) Gel-3; (d) Gel-4.

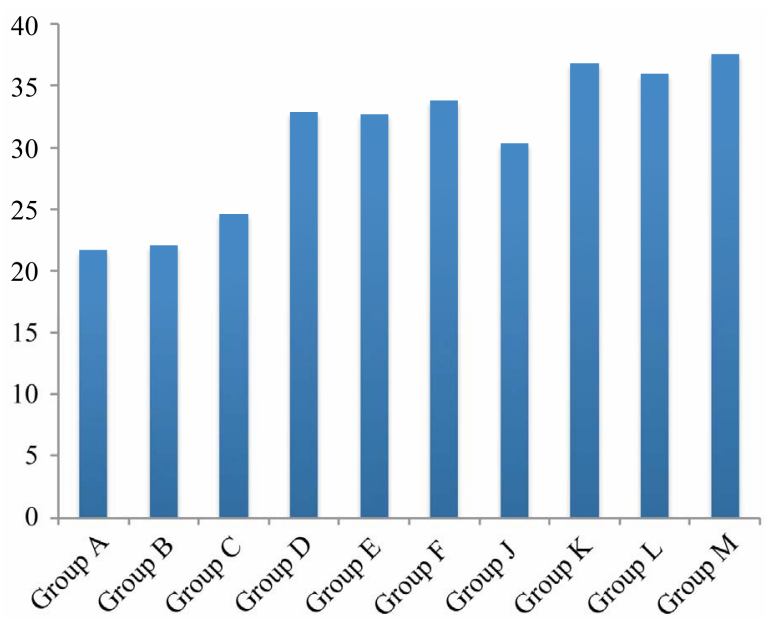

Figure 2. Shear bond strength (MPa) of 10 Groups after 24 hours of bonding to dentine.

treated with phosphoric acid (C). Furthermore, the presence of the anti-oxidants (resveratrol, propolis and $\beta$ carotene) improved the shear bond strength with $(\mathrm{K}, \mathrm{L}$ and $\mathrm{M}$ ) or without (D, E, F) phosphoric acid treatment. The treatment of dentine with phosphoric acid and antioxidants gave somewhat (not significantly) higher values $(\mathrm{K}, \mathrm{L}, \mathrm{M})$ than without phosphoric acid (D, E, F).

In general, all 10 groups gave a relapse in the shear bond strength after a 6 months (Figure 3) storage period compared to 24 hours (Compare groups in Figure 2 to that in Figure 3). A statistically significant difference (decrease) was found between $\mathrm{C}$ ( 24 hours) relative to $\mathrm{C}$ after 6 month groups $(\mathrm{p}<0.02)$. Groups D, E, and F after 24 hours were statistically significantly different (higher) than D, E, and F after 6 months ( $\mathrm{p}<0.01)$. Group $\mathrm{C}$ also differed significantly from $\mathrm{J}$ after 24 hours and 6 month $(\mathrm{p}<0.01)$ as well significant difference was found to be between groups $\mathrm{J}$ and $\mathrm{K}, \mathrm{L}$ and $\mathrm{M}$ (after 24 hours and 6 month) $(\mathrm{p}<0.01)$.

The results of this study suggested that the optimum values for the strengthening of dentine can be achieved through the immediate treatment with resveratrol, betacarotene and propolis with the increase of dentine bond strength (Figure 2).

The results further demonstrated that resveratrol, $\beta$-carotene and propolis showed synergistic effect with chitosan containing hydrogels on significant improvement in bond strength after $24 \mathrm{~h}$ and 6 month (Figure 3).

This results are in accordance with the previously reported observations by Upin [10] on the performance of sodium ascorbate hydrogels on the bond strength of composite material as well ability of the newly developed hydrogels to counteract the prohibitive oxygen layer formation on the interface of the composite and adhesive material as well as allow the material to be easily applied in the desired area due to the higher viscosity 


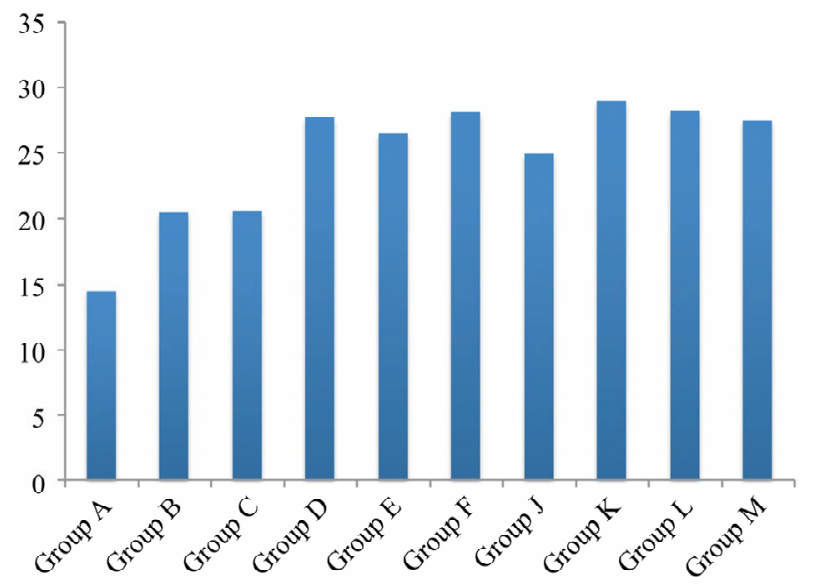

Figure 3. Shear bond strength (MPa) of 10 Groups after 6 month of bonding to dentine.

and better handling properties in comparison to aqueous solution of corresponding active agents.

\section{DISCUSSION}

Titley and others [11] reported that dentin and dentinal fluid can act as a peroxide and oxygen reservoir, which may be present at the bonding interface, inhibit the polymerization reaction and reduce bond strength $[12,13]$. Thus, an increase in the antioxidant strength of the application, which may vary according to the antioxidant agent, and/or an increase in the concentration used for dentin, may be indicated in an endeavor to neutralize the free oxygen present in a higher amount in dentin than in enamel.

The results of this study suggested that optimum results for the increased dentin bond strength can be achieved through out the immediate treatment with Gel-1, Gel-2, Gel-3 or Gel-4 (Figure 2). The additional advantage of the system may suggest that, antioxidant release from chitosan gel depends on the physical network structure (open cell like structure) as well as $\mathrm{pH}$ properties and flexibilities of the material. Antioxidant release occurs through the pores of the low polymer concentration while chitosan concentration increment resulted in more cross-linking of the network structure; consequently slower antioxidant release from the gel base was achieved and therefore weaker adhesive properties of the materials such as Gel-1 in case of groups [9]. The possible influence of this release on the tooth pulp fibroblast cells were also investigated and shown in Figure 4.

It was shown by others [13] and us earlier [14], that the swelling properties and antioxidant release from gels were increased under acidic conditions due to the protonation of the primary amino group on chitosan. Chain relaxation due to protonation of amino groups leads to a faster hydrogen bond dissociation and efficient solvent diffusion.
Box \& Whisker Plot

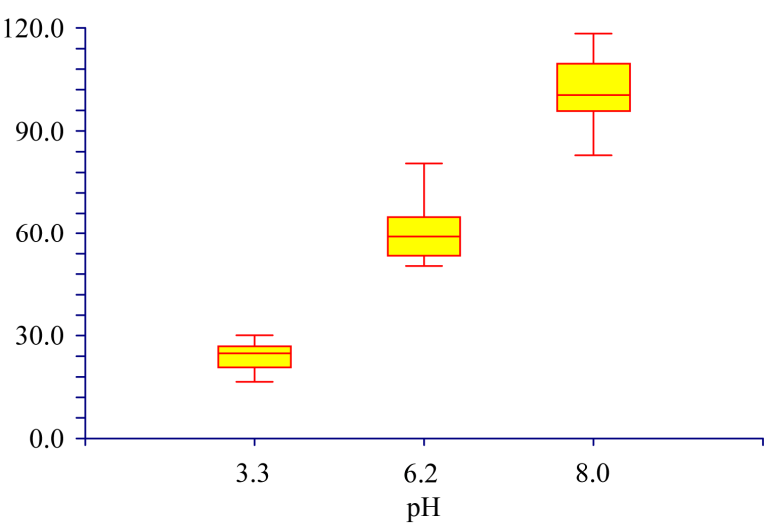

Figure 4. The Box \& Whisker plot of the \% survival rate of mouse $3 \mathrm{~T} 3$ fibroblast cells when exposed to resveratrol (33\%), propolis (68\%) and $\beta$-carotene $(92 \%)$. The maximum and minimum values were given. The intermediary box represents the position of $50 \%$ of the values and the line within the box shows the median values.

Thus, the appreciable increase in water uptake at lower $\mathrm{pH}$ values can be attributed to the high porosity of the gels, which seems to govern the diffusion of the solvent in the gel matrix, and thus, the release of the antioxidant from the gel [15].

The additional benefit of using chitosan:antioxidant system as a bonding/prebonding to dentin system lies in its ability to show favorable immediate results (Figure 2) in terms of bonding effectiveness as well as the durability of resin-dentin bonds for a prolonged time (up to 6 months, Figure 3). It is well documented that the hydrostatic pulpal pressure, the dentinal fluid flow and the increased dentinal wetness in vital dentin can affect the intimate interaction of certain dentin adhesives with dentinal tissue. Bond degradation occurs via water sorption, hydrolysis of ester linkages of methacrylate resins, and activation of endogenous dentin matrix metalloproteinases. Therefore, the newly developed chitosan: antioxidant systems might be able to address shortfalls in the current perspectives for improving bond durability through understanding factors affecting the long-term bonding performance of modern adhesives and addresses the current perspectives for improving bond durability.

This positive effect of the antioxidants and the slow release thereof lead to the question of what their effect on pulpal cells would be and therefore to the cytotoxic study. For this paper each cell test survival rate determination was done simultaneously with the control to standardize. To calculate the $\%$ viable cells between the controls and the test samples, each raw test value (in the presence of the acid or antioxidant) was divided by the median of the corresponding control survival values [16-18]. Normally the cell survival rate will depend on a number of factors: type of substance to be tested, the concentration of the 
substance, the type of cell-line used and the time of cell exposure to the substance to be tested. For all three antioxidants $1 \mathrm{mg}$ of antioxidant/ml growth medium over a 24 hour period was tested for their survival rates. This can be considered as a high concentration and well in the top range of concentrations tested for other products, similar to about $1000 \mu \mathrm{g} / \mathrm{ml}$ concentration cytotoxic effect of medicinal plants $[19,20]$. An exposure period of 24 hours can also be accepted as a long period [19,21-23]. It was reported that the median lethal concentration that kills $50 \%$ of the larvae within $24 \mathrm{~h}$ of contact with the extract [LC(50)] was less than $1000 \mu \mathrm{g} / \mathrm{ml}$ for $4(13 \%)$ species [19]. Ruffa [20], reported a $100 \%$ inhibitory concentration of below $500 \mu \mathrm{g} / \mathrm{ml}$ for 8 selected Argentine medicinal plant extracts over 24 hours on human hepatocellular carcinoma cell line.

In this study it was found (Table 3) that the $\mathrm{pH}$ levels of the 3 different substances in water differed mainly from 3.3 (propolis) through 6.2 (resveratrol) to 8.0 ( $\beta$-carotene). Therefore, to determine the effects of these $\mathrm{pH}$ levels on the cell survival rates, the growth mediums were adjusted to the 3 mentioned $\mathrm{pH}$ levels.

A large influence of the 3 different $\mathrm{pH}$ values on the cell survival rate was found (Figures 5 and 6). The survival rate at a $\mathrm{pH}$ of 6.2 was $60 \%$ and only $24 \%$ at a $\mathrm{pH}$ of 3.3. The cell survival rate and the $\mathrm{pH}$ values nearly showed a direct relationship (Figures 5 and 6). At the $\mathrm{pH}$ of 8.0 the cell survival rate of the $3 \mathrm{~T} 3$ cells were found to be at a $100 \%$ level. It showed the importance of always using growth mediums at a $\mathrm{pH}$ of 8.0 (for Balb/c mouse

Table 3. The $\mathrm{pH}$ levels of resveratrol, $\beta$-carotene and propolis just in water.

\begin{tabular}{cc}
\hline Name of antioxidant & $\mathrm{pH}$ values \\
\hline Resveratrol & 6.2 \\
$\beta$-Carotene & 8.0 \\
Propolis & 3.3 \\
\hline
\end{tabular}

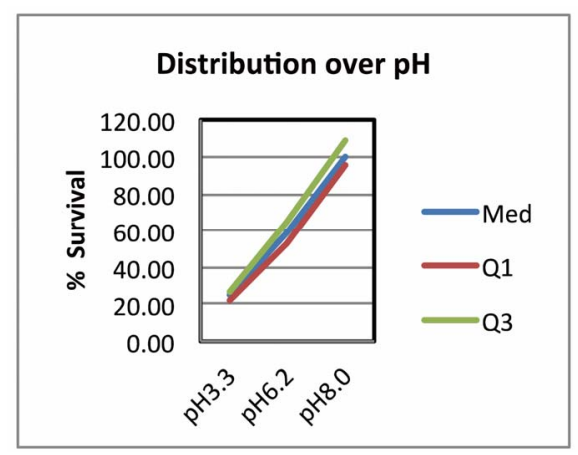

Figure 5. The distribution of the data over $\mathrm{pH}$. It shows the median 2nd quartile, first quartile and 3rd quartile ranges. Where: Med. the median and 2nd quartile, Q1 the first quartile and Q3 the 3rd quartile.

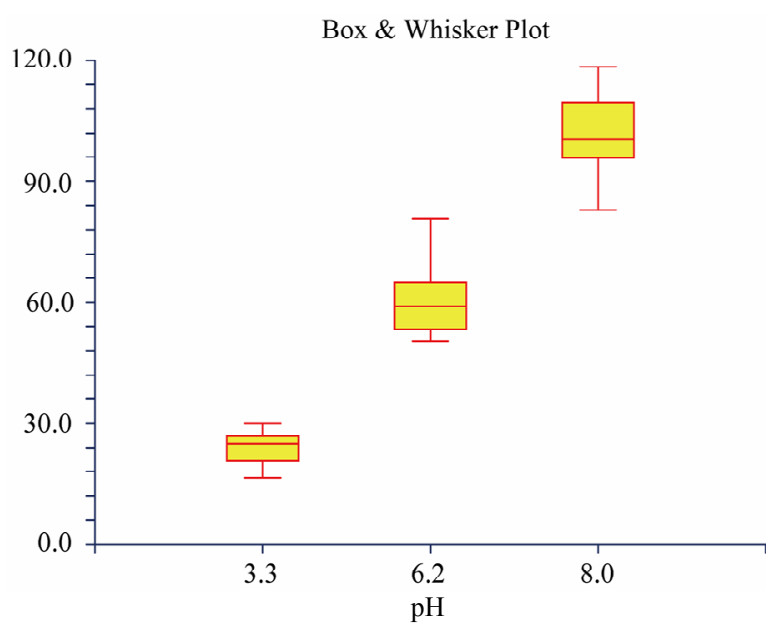

Figure 6. The Box and Whisker plots of the percentage cell survival rates of mouse Balb/c 3T3 fibroblast cells when exposed to 3 different $\mathrm{pH}$ values. The maximum and minimum values were given. The intermediary box represents the position of $50 \%$ of the values and the line within the box showed the median values.

$3 \mathrm{~T} 3$ fibroblast cells) and to adjust the $\mathrm{pH}$ of the medium if necessary. Furthermore, it can also be seen that the negative effect of a lower $\mathrm{pH}$ on the survival rate became higher at lower $\mathrm{pH}$ levels resulting in a more narrow distribution of the results (Figure 5) at a $\mathrm{pH}$ of 3.3 relative to a $\mathrm{pH}$ of 8.0. Fresney [24] also reported that most celllines grow well at $\mathrm{pH} 7.4$ and that normal fibroblast lines perform best at $\mathrm{pH} 7.4$ to 7.7 , but that it might differ between different cell lines. In our hands over years we found that Balb/c mouse 3T3 fibroblast cells grew the best at a $\mathrm{pH}$ of 8.0 and therefore this $\mathrm{pH}$ was chosen as the ideal working $\mathrm{pH}$ for the specific cell line. Therefore, we used a growth medium at a $\mathrm{pH}$ of 8.0 to test for the effect of the 3 antioxidants on the cell survival rates.

The sequence of the survival rate was found to be: $\beta$-carotene $>$ propolis $>$ resveratrol (Figure 4). It was reported that resveratrol suppressed lymphocyte proliferation, development of cell-mediated cytotoxicity and cytokine production [25] and that it triggers CD95 signaling-dependent apoptosis in human tumor cells [26]. Furthermore, it caused a $70 \%$ growth inhibition of CACo-2 cells [27]. It was reported [28] that resveratrol could be an anti-cancer agent for breast cancer. It was also reported that resveratrol suppressed cancer metabolism [29]. However, Yoshino [30], reported that resveratrol supplementation did not improve metabolic effects in non-obese, post-menopausal women with normal glucose tolerance. These differences found between 3T3 cells and others could be due to concentration, cell type and exposure time. Exposure of 3T3 cells to propolis was found to result in a cell survival rate of $68 \%$ (Figure 4). This is in agreement to various reports which showed the cytotoxic activities of propolis [31] on various cell types [21]. Furthermore, a 
positive effect of propolis on enamel micro-hardness was also reported [32]. Propolis has been used as an ointment since $350 \mathrm{BC}$, the time of Aristotle [33]. It has been used for abscesses; for healing wounds and tumors; and Egyptians have used it for mummification [33]. Propolis was also reported to increase the micro-hardness of tooth enamel due to particular components of mineralization activity in propolis [32]. Relatively to our high concentration $(1 \mathrm{mg} / \mathrm{ml})$ a low $\beta$-carotene concentration $(\sim 40$ $\mathrm{mg} / \mathrm{l})$ was reported to substantiate a selective cytotoxic effect on human tumor cells [23]. However, we could not see an influence of $\beta$-carotene (93\%) on 3T3 cells at a much high concentration ( $1 \mathrm{mg} / \mathrm{ml}$; Figure 4). In another study, Alija [22] could also not find any cytotoxic effect on hepatocytes but at a relatively low concentration of $\sim 5$ $\mathrm{mg} / \mathrm{l}$. A 93\% cell survival rate can be considered as having no influence.

To conclude: The antioxidant-chitosan hydrogels significantly improved bonding to dentine with or without phosphoric acid treatment. The $\mathrm{pH}$ of the growth medium had a high influence on the cell survival rate of Balb/c mouse 3T3 fibroblast cells. The release of the antioxidant $\beta$-carotene would not have an influence on the pulp cells.

\section{ACKNOWLEDGEMENTS}

This study is financially supported by the DDF fund of the South African Dental Association. VTP would like to thank Dr Vanessa Reher for invaluable support through out the challenging times. VTP would like to acknowledge partial financial support by the School of Dentistry and Oral Health, Griffith University for the travel research fellowship.

\section{REFERENCES}

[1] Schmalz, G. (1997) Concepts in biocompatibility testing of dental restorative materials. Clinical Oral Investigations, 1, 154-162. doi:10.1007/s007840050027

[2] Peumans, M., Kanumilli, P., De-Munck, J., Van Landuyt, K., Lambrechts, P. and Van Meerbeek, B. (2005) Clinical effectiveness of contemporary adhesives: A systematic review of current clinical trials. Dental Materials, 21, 864-881. doi:10.1016/j.dental.2005.02.003

[3] Murray, P.E., Windsor, L.J., Hafez, A.A., Stevenson, R.G. and Cox, C.F. (2003) Comparison of pulp responses to resin composites. Operative Dentistry, 28, 242-250.

[4] Schweikl, H., Spagnuolo, G. and Schmalz, G. (2006) Genetic and cellular toxicology of dental resin monomers. Journal of Dental Research, 85, 870-877. doi:10.1177/154405910608501001

[5] Chen, R.S., Liu, C.C., Tseng, W.Y., Jeng, J.H. and Lin, C.P. (2003) Cyto toxicity of three dentin bonding agents on human dental pulp cells. Journal of Dentistry, 31, 223229. doi:10.1016/S0300-5712(02)00088-X

[6] Chen, R.S., Liuiw, C.C., Tseng, W.Y., Hong, C.Y., Hsieh, C.C. and Jeng, J.H. (2001) The effect of curing light intensity on the cytotoxicity of a dentin-bonding agent.
Operative Dentistry, 26, 505-510.

[7] De Souza Costa, C.A., Vaerten, M.A., Edwards, C.A. and Hanks, C.T. (1999) Cytotoxic effects of current dental adhesive systems on immortalized odontoblast cell line MDPC-23. Dental Materials, 15, 434-441. doi:10.1016/S0109-5641(99)00071-8

[8] Vajrabhaya, L.O., Pasasuk, A. and Harnirattisai, C. (2003) Cytotoxicity evaluation of single component dentin bonding agents. Operative Dentistry, 28, 440-444.

[9] Perchyonok, V.T., Zhang, S. and Oberholzer, T. (2012) Alternative chitosan based drug delivery system to fight oral mucositis: Synergy of conventional and bioactives towards the optimal solution. Current Nanoscience, 8, 541-547. doi:10.2174/157341312801784320

[10] Mosmann, T. (1983) Rapid colorimetric assay for cellular growth and survival: Application to proliferation and cytotoxicity assays. Journal of Immunological Methods, 65, 55-63. doi:10.1016/0022-1759(83)90303-4

[11] Titley, K.C., Smith, D.C., Chernecky, R., Maric, B. and Chan, A. (1995) An SEM examination of etched dentin and the structure of the hybrid layer. Journal of Canadian Dental Association, 61, 887-894.

[12] Dabas, D., Patil, A.C. and Uppin, V.M. (2011) Evaluation of the effect of concentration and duration of application of sodium ascorbate hydrogel on the bond strength of composite resin to bleached enamel. Journal of Conservative Dentistry, 14, 356-360. doi:10.4103/0972-0707.87197

[13] Ravi Kumar, M.N.V. (2001) A review of chitin and chitosan applications. Reactive and Functional Polymers, 46, 1-27. doi:10.1016/S1381-5148(00)00038-9

[14] Perchyonok, V.T., Zhang, S. and Oberholzer, T. (2012) Towards development of novel chitosan based drug delivery prototypes devices for targeted delivery drug therapy at the molecular level in aqueous media. Current Organic Chemistry, 16, 2437-2439.

[15] Petri, D.F., Donegá, J., Benassi, A.M. and Bocangel, J.A. Preliminary study on chitosan modified glass ionomer restoratives. Dental Materials, 23, 1004-1010. doi:10.1016/j.dental.2006.06.038

[16] Grobler, S.R., Olivier, A., Moodley, D. and van Wyk Kotze, T.J. (2008) Cytotoxicity of recent bonding agents on mouse fibroblast cells. Quintessence International, 39, 511-516.

[17] Grobler, S.R., Olivier, A., Moodley, D. and van Wyk Kotze, T.J. (2004) Cytotoxicity of two concentrations of a dentine bonding agent on mouse 3T3 and human pulp fibroblast cell-lines. Journal of the South African Dental Association, 59, 368-372.

[18] Grobler, S.R., Oberholzer, T.G., Rossouw, R.J. and van Wyk Kotze, T.J. (2007) Microleakage and confocal laser studies of two single step self-etching bonding agents/ systems. Quintessence International, 38, 525.

[19] Coe, F.G., Parikh, D.M., Johnson, C.A. and Anderson, G.J. (2012) The good and the bad: Alkaloid screening and brine-shrimp bioassays of aqueous extracts of 31 medicinal plants of eastern Nicaragua. Pharmaceutical Biology, 50, 384-392. doi:10.3109/13880209.2011.608077 
[20] Ruffa, M.J., Ferraro, G., Wagner, M.L, Calcagno, R.H. and Campo, L. (2002) Cavallaros cytotoxic effect of Argentine medicinal plant extracts on human hepatocellular carcinoma cell line. Journal of Ethnopharmacology, 79, 335-339. doi:10.1016/S0378-8741(01)00400-7

[21] Chen, C., Weng, M., Wu, C. and Lin, J. (2004) Comparison of radical scavenging activity, cytotoxic effects and apoptosis induction in human melanoma cells by Taiwanese propolis from different sources. Evidence-Based Complementary and Alternative Medicine, 1, 175-185. doi:10.1093/ecam/neh034

[22] Alija, A.J., Bresgen, N., Sommerburg, O., Siems, W. and Eckl, P.M. (2004) Cytotoxic and genotoxic effects of $\beta$-carotene breakdown products on primary rat hepatocytes. Oxford Journals, 25, 827-831. doi:10.1093/carcin/bgh056

[23] Schwartz, J. and Shklar, G. (1992) The selective cytotoxic effect of carotenoids and $\alpha$-tocopherol on human cancer cell lines in vitro. Journal of Oral and Maxillofacial Surgery, 50, 367-373. doi:10.1016/0278-2391(92)90400-T

[24] Freshney, I. (2007) Culture of animal cells. John Wiley and Sons, New Jersey.

[25] Gao, X., Xu, Y.X., Janakiraman, N., Chapman, R.A. and Gautam, S.C. (2001) Immunomodulatory activity of resveratrol: Suppression of lymphocyte proliferation, development of cell-mediated cytotoxicity, and cytokine production. Biochemical Pharmacology, 62, 1299-1308. doi:10.1016/S0006-2952(01)00775-4

[26] Clément, M., Hirpara, J.L., Chawdhury, S. and Pervaiz, S. (1998) Chemopreventive agent resveratrol, a natural product derived from grapes, triggers $\mathrm{CD}_{95}$ signalling-dependent apoptosis in human tumor cells. Blood, 92, 9961002.
[27] Scneider, Y., Vincent, F., Duranton, B., Badolo, L., Gossé, F., Bergmann, C., Seiler, N. and Raaul, F. (2002) Anti-proliferative effect of resveratrol, a natural component of grapes and wine, on human colonic cancer cells. Cancer Letters, 158, 85-91. doi:10.1016/S0304-3835(00)00511-5

[28] Nakagawa, H., Uemura, Y., Shikata, H., Hioki, K. and Tsubura, A. (2001) Resveratrol inhibits human breast cancer cell growth and may mitigate the effect of linoleic acid, a potent breast cancer cell stimulator. Journal of Cancer Research and Clinical Oncology, 126, 258-264. doi:10.1007/s004320000190

[29] Iqbal, M.A. and Bamezai, R.N.K. (2012) Resveratrol inhibits cancer cell metabolism by down regulating pyruvate kinase M2 via inhibition of mammalian target of rapamycin. PLoS ONE, 7, e36764. doi:10.1371/journal.pone.0036764

[30] Yoshino, J., Conte, C., Fontana, L., Mittendorfer, B., Imai, S., Schechtman, K.B., Charles, G., Kunz, I., Fanelli, F.R., Patterson, B.W. and Samuel, K.S. (2012) Resveratrol supplementation does not improve metabolic function in nonobese women with normal glucose tolerance. Cell Metabolism, 16, 658-664.

[31] Banskota, A.H., Tezuka, Y., Prasain, J.K., Matsushige, K., Saiki, I. and Kadota, S. (1998) Chemical constituents of Brazilian propolis and their cytotoxic activities. Journal of Natural Products, 61, 896-900.

[32] Giamalia, I., Steinberg, D., Grobler, S. and Gedalia, I. (1999) The effect of propolis exposure on microhardness of human enamel in vitro. Journal of Oral Rehabilitation, 26, 472-475. doi:10.1046/j.1365-2842.1999.00472.x

[33] Medline Plus (2012) Propolis. http://www.nlm.nih.gov/medlineplus/druginfo/natural/390. $\underline{\mathrm{html}}$ 